\title{
AB-QTL analysis in spring barley: II. Detection of favourable exotic alleles for agronomic traits introgressed from wild barley (H. vulgare ssp. spontaneum)
}

Received: 3 May 2005 / Accepted: 15 January 2006/Published online: 14 February 2006

(C) Springer-Verlag 2006

\begin{abstract}
The objective of the present study was to identify favourable exotic Quantitative Trait Locus (QTL) alleles for the improvement of agronomic traits in the $\mathrm{BC}_{2} \mathrm{DH}$ population $\mathrm{S} 42$ derived from a cross between the spring barley cultivar Scarlett and the wild barley accession ISR42-8 (Hordeum vulgare ssp. spontaneum). QTLs were detected as a marker main effect and/or a marker $\times$ environment interaction effect $(M \times E)$ in a three-factorial ANOVA. Using field data of up to eight environments and genotype data of 98 SSR loci, we detected 86 QTLs for nine agronomic traits. At 60 QTLs the marker main effect, at five QTLs the $M \times E$ interaction effect, and at 21 QTLs both the effects were significant. The majority of the $M \times E$ interaction effects were due to changes in magnitude and are, therefore, still valuable for marker assisted selection across environments. The exotic alleles improved performance in $31(36.0 \%)$ of 86 QTLs detected for agronomic traits. The exotic alleles had favourable effects on all analysed quantitative traits. These favourable exotic alleles were detected, in particular on the short arm of chromosome $2 \mathrm{H}$ and the long arm of chromosome $4 \mathrm{H}$. The exotic allele on $4 \mathrm{HL}$, for example, improved yield by $7.1 \%$. Furthermore, the presence of the exotic allele on 2HS increased the yield component traits ears per $\mathrm{m}^{2}$ and thousand grain weight by $16.4 \%$ and $3.2 \%$, respectively. The present study, hence, demonstrated
\end{abstract}

Communicated by G. Wenzel

M. von KorffH. Wang · J. Léon · K. Pillen $(\bowtie)$

Institute of Crop Science and Resource Conservation,

Chair of Crop Science and Plant Breeding, University of Bonn,

Katzenburgweg 5, 53115 Bonn, Germany

E-mail: k.pillen@uni-bonn.de

Fax: + 49-228-732045

Present address: M. von Korff

Department of Biochemistry and Biology, University of Potsdam, Karl-Liebknecht-Str. 24-25, Haus 26, 14476 Golm, Germany

Present address: H. Wang

Gansu Agricultural University, Yinmencun 1, 730070 Anningqu, Lanzhou, China that wild barley does harbour valuable alleles, which can enrich the genetic basis of cultivated barley and improve quantitative agronomic traits.

Keywords Hordeum vulgare ssp. spontaneum. Barley $\cdot$ SSR $\cdot$ AB-QTL $\cdot$ Yield

\section{Introduction}

Based on the promising results of advanced backcross quantitative trait locus (AB-QTL) analyses conducted in tomato, Gur and Zamir (2004) proposed a new paradigm in plant breeding: the use of natural variation present in the wild relatives of modern crop plants to lift yield barriers in plant breeding. They predicted that for crops with a rather narrow genetic basis, but rich biodiversity resources, the introgression of exotic germplasm could lead to dramatic improvements in yield and other quality traits. For barley, the beneficial effect of exotic genes on biotic (Backes et al. 2003; Fischbeck and Jahoor 1991; Zeller 1998) and abiotic (Jefferies et al. 1999) stresses and to some extent on quality traits (Erkkilä 1998) has already been demonstrated. The potential use of wild germplasm for the improvement of agronomic traits, however, is still a matter of controversy. Few studies on yield improvement have so far attempted to work with exotic germplasm, since the majority of genes present in exotic germplasm have strong negative effects on agronomic performance. As such, the challenge remains to identify favourable exotic alleles and to introduce them into breeding programs. As a modification of the QTL mapping approach, Tanksley and Nelson (1996) have developed the ABQTL strategy, particularly suitable to unmask valuable exotic alleles and to introgress them into elite breeding material. Since QTL detection is carried out in advanced backcross populations, problems associated with considerable phenotypic variation and linkage drag in interspecific crosses are reduced. So far, several reports on the application of the AB-QTL strategy are available 
for tomato (Tanksley et al. 1996; Fulton et al. 1997, 2000, 2002; Bernacchi et al. 1998); rice (Xiao et al. 1996, 1998; Moncada et al. 2001; Brondani et al. 2002; Septiningsih et al. 2003; Wu et al. 2004); maize (Ho et al. 2002); pepper (Rao et al. 2003); wheat (Huang et al. 2003, 2004; and barley (Pillen et al. 2003, 2004; Matus et al. 2003; Li et al. 2004). The favourable effects of the wild barley accession ISR101-23 on yield in two barley feeding varieties recorded by Pillen et al. (2003, 2004) encourage further investments in the development of AB-populations for the genetic exploitation of diverse exotic barley germplasms. The demonstrated genetic diversity in wild barley (Hordeum vulgare ssp. spontaneum, Turpeinen et al. 2001; Baek et al. 2003) suggests a not yet exploited wealth of novel exotic alleles.

Therefore, the aim of the present study was to identify favourable exotic alleles in a $\mathrm{BC}_{2} \mathrm{DH}$ population (S42) derived from a cross of the malting barley cultivar Scarlett with the wild barley accession ISR42-8 from Israel. Favourable effects of the exotic donor accession ISR 42-8 on disease resistances in S42 have already been demonstrated by von Korff et al. (2005).

\section{Materials and methods}

Plant material

The development of the population S42 with 301 $\mathrm{BC}_{2} \mathrm{DH}$ lines originating from the cross of the German spring barley variety Scarlett with the Israeli wild barley accession ISR42-8 is described in detail in von Korff et al. (2004).

\section{Molecular characterisation}

The $\mathrm{BC}_{2} \mathrm{DH}$ population was genotyped with $98 \mathrm{SSR}$ markers as described in von Korff et al. (2004).

\section{Phenotypic evaluation of agronomic traits}

Phenotypic evaluation of yield and yield component traits of the population S42 was carried out under field conditions at four different locations during the seasons 2003 (03) and 2004 (04). The test locations were the experimental station Dikopshof (D03, D04, University of Bonn, West Germany), and the breeders' experimental stations in Gudow (G03, G04, Nordsaat Saatzucht, North Germany), Irlbach (I03, I04, Dr. J. Ackermann, South Germany) and Morgenrot (M03, M04, Saatzucht Josef Breun, East Germany). The field experiment was designed in randomised plots without replications. As a control, the recurrent parent Scarlett was tested with 20 replications per block. Net plot sizes $\left(5.0-9.0 \mathrm{~m}^{2}\right)$, seed density (300-330 kernels $\left./ \mathrm{m}^{2}\right)$, nitrogen fertilization (60$80 \mathrm{~kg} \mathrm{~N} /$ ha) taking into account the $N_{\text {min }}$ content in the soil, and field management were in accordance with the local practice. The grain was harvested with a small plot harvester at maturity. The recorded traits and methods of measurement are listed in Table 1.

\section{Statistical analyses}

Statistical analyses were carried out with SAS version 9.1 (SAS Institute 2003). Genetic correlation between trait values were calculated with the ls means of $\mathrm{BC}_{2} \mathrm{DH}$ lines averaged across environments. The detection of QTLs was carried out using the following mixed hierarchical model in the GLM procedure:

$Y_{i j k m}=\mu+M_{i}+L_{j}\left(M_{i}\right)+E_{k}+M_{I} \times E_{k}+\varepsilon_{m(j i k)}$

where $\mu$ is the general mean, $M_{i}$ is the fixed effect of the $i$ th marker genotype, $L_{j}\left(M_{i}\right)$ is the random effect of the $j$ th $B C_{2} D H$ line nested in the $i$ th marker genotype, $E_{k}$ is the random effect of the $k$ th environment, $M_{i} \times E_{k}$ is the random interaction effect of the $i$ th marker genotype with the $k$ th environment, $\varepsilon_{m(j i k)}$ is the error of $Y_{i j k m}$. Marker main effects and $\mathrm{M} \times \mathrm{E}$ interactions are interpreted as putative QTLs, if the $P$ value calculated by the Type III sums of squares is less than 0.01 (Pillen et al. 2003). Linked significant markers with a distance of $\leq 20 \mathrm{cM}$ and showing the same effect were interpreted as a single putative QTL, and only the most significant marker from each group of linked loci is recorded. In order to meet the ANOVA assumption of normality, the data for lodging (LOF) were transformed by calculating the inverse of the square root. The relative performance of the homozygous exotic genotype (RP $H s p]$ ) was calculated as described in von Korff et al. (2005). The genetic variance explained by a marker $\left(R_{M}^{2}\right)$, and by an $M \times E$ interaction $\left(R_{M \times E}^{2}\right)$ was calculated as follows:

$R_{M}^{2}=\mathrm{SQ}_{M} / \mathrm{SQ}_{g}, R_{M \times E}^{2}=\mathrm{SQ}_{M \times E} / \mathrm{SQ}_{g}$

$\mathrm{SQ}_{M}$ and $\mathrm{SQ}_{M \times E}$ correspond to the sums of squares of $M$ and $M \times E . \mathrm{SQ}_{g}$ was calculated as the type III sums of square of the $\mathrm{BC}_{2} \mathrm{DH}$ lines in the following ANOVA model:

$Y_{i j k}=\mu+L_{i}+E_{j}+\varepsilon_{j i k}$,

where $L_{i}$ is the fixed effect of the $i$ th $\mathrm{BC}_{2} \mathrm{DH}$ line and $E_{j}$ is the random effect of the $j$ th environment. $\mathrm{SQ}_{g}$ was calculated for every marker separately to account for the occurrence of missing genotype data. If both, the marker main effect and the $M \times E$ interaction effect are significant, $R^{2}$ is calculated as $\mathrm{SQ}_{M} / \mathrm{SQ}_{G}$.

\section{Results}

\section{Correlations}

A total of 34 significant correlations were detected between nine traits (Table 2). The yield exhibited negative correlations with brittleness, plant height, lodging at 
Table 1 List of nine quantitative traits investigated in up to eight environments

\begin{tabular}{|c|c|c|c|c|}
\hline Abbr. ${ }^{\mathrm{a}}$ & Trait & Method of measurement & Value $^{\mathrm{b}}$ & Environment tested ${ }^{\mathrm{c}}$ \\
\hline BRT & Brittleness & $\begin{array}{l}\text { Visual assessment of brittleness as present (1) or } \\
\text { absent (2) before harvest. }\end{array}$ & - & D03, D04 \\
\hline HEA & Days until heading & $\begin{array}{l}\text { Number of days from sowing until emergence of } \\
50 \% \text { of ears on main tillers. }\end{array}$ & - & $\begin{array}{l}\text { D03, D04, G03, G04, I03, I04, } \\
\text { M03, M04 }\end{array}$ \\
\hline HEI & Plant height & $\begin{array}{l}\text { Average plant height measured from soil surface to } \\
\text { tip of spike (including awns) two weeks after } \\
\text { flowering. }\end{array}$ & - & $\begin{array}{l}\text { D03, D04, G03, G04, I03, I04, } \\
\text { M03, M04 }\end{array}$ \\
\hline $\mathrm{HI}$ & Harvest index & $\begin{array}{l}\text { Ratio of generative to vegetative biomass, calculated } \\
\text { from a single row of } 50 \mathrm{~cm} \text { at maturity. }\end{array}$ & + & D03, D04 \\
\hline LOF & Lodging at flowering & $\begin{array}{l}\text { Visual rating of the severity of lodging at flowering, } \\
\text { where } 1 \text { represents no lodging and } 9 \text { represents } \\
\text { total lodging. }\end{array}$ & - & $\begin{array}{l}\text { D03, D04, G03, G04, I03, I04, } \\
\text { M03, M04 }\end{array}$ \\
\hline MAS & Vegetative dry biomass & $\begin{array}{l}\text { Total dry biomass above ground, collected from a } \\
\text { row of } 50 \mathrm{~cm} \text { at maturity. }\end{array}$ & + & D03, D04 \\
\hline
\end{tabular}

${ }^{a}$ Data for LOF were transformed by $\mathrm{x}^{-2}$ transformation of raw data prior to ANOVA.

$\mathrm{b}$ The breeding goals for the investigated traits were defined according to breeding progams for spring malting barley, where (-) indicates that a reduction and $(+)$ that an increase of the trait values is desirable.

${ }^{c}$ Combination of the location [Dikopshof (D), Gudow (G), Irlbach (I), Morgenrot (M)] and the year [2003 (03), 2004 (04)].

flowering and biomass ranging from -0.31 to -0.56 , and positive correlations with ears per $\mathrm{m}^{2}$, days until heading and harvest index of $0.26,0.33$ and 0.55 , respectively. Ears per $\mathrm{m}^{2}$ showed a positive correlation with days until heading, harvest index and yield between 0.15 and 0.58 and a negative correlation with plant height, lodging at flowering and thousand grain weight of $-0.60,-0.42$ and -0.21 , respectively. In order to test the hypothesis that a high percentage of exotic germplasm $\mathrm{P}[H s p]$ has a negative influence on agronomic performance, the proportion of exotic alleles in a $\mathrm{BC}_{2} \mathrm{DH}$ lines was calculated. No strong correlations between $\mathrm{P}[H s p]$ and other traits were recorded. However, weak negative correlations of $\mathrm{P}[H s p]$, were revealed with days until heading, biomass, thousand grain weight and yield and weak positive correlations were found with brittleness and lodging at flowering.

\section{QTL analysis}

The ANOVA revealed 248 significant marker trait associations with 175 marker main effects and 24 marker environment interaction effects. For 49 markers trait associations both, the marker main and the $\mathrm{M} \times \mathrm{E}$ interaction effects were significant. Due to linkage between markers, these effects were summarised to 86 putative QTLs for nine agronomic traits (Table 3, Fig. 1). At 60 QTLs the marker main effect, at five QTLs the $\mathrm{M} \times \mathrm{E}$ interaction effect, and at 21 QTLs both effects
Table 2 Correlation coefficients (r) according to Pearson between nine traits and the percentage of exotic germplasm $(\mathrm{P}[H s p])$ in the $\mathrm{BC}_{2} \mathrm{DH}$ population $\mathrm{S} 42$

\begin{tabular}{|c|c|c|c|c|c|c|c|c|c|}
\hline Traits & EAR & HEA & HEI & $\mathrm{HI}$ & LOF & MAS & TGW & YLD & $\mathrm{P}[H s p]$ \\
\hline BRT & $\begin{array}{l}-0.26 \\
* * *\end{array}$ & $\begin{array}{l}-0.24 \\
* * *\end{array}$ & $\begin{array}{l}0.32 \\
* * *\end{array}$ & $\begin{array}{l}-0.43 \\
* * *\end{array}$ & $\begin{array}{c}0.34 \\
* * *\end{array}$ & -0.06 & 0.03 & $\begin{array}{l}-0.50 \\
* * *\end{array}$ & $\begin{array}{l}0.23 \\
* * *\end{array}$ \\
\hline EAR & & $\begin{array}{l}0.15 \\
*\end{array}$ & $\begin{array}{l}-0.60 \\
* * *\end{array}$ & $\begin{array}{l}0.58 \\
* * *\end{array}$ & $\begin{array}{l}-0.42 \\
* * *\end{array}$ & 0.10 & $\begin{array}{l}-0.21 \\
* * *\end{array}$ & $\begin{array}{l}0.26 \\
* * *\end{array}$ & 0.08 \\
\hline HEA & & & $\begin{array}{l}-0.46 \\
* * *\end{array}$ & $\begin{array}{l}0.43 \\
* * *\end{array}$ & $\begin{array}{l}-0.65 \\
* * *\end{array}$ & $\begin{array}{l}0.17 \\
*\end{array}$ & $\begin{array}{l}-0.15 \\
* *\end{array}$ & $\begin{array}{l}0.33 \\
* * *\end{array}$ & $\begin{array}{c}-0.13 \\
*\end{array}$ \\
\hline HEI & & & & $\begin{array}{l}-0.85 \\
* * *\end{array}$ & $\begin{array}{l}0.87 \\
* * *\end{array}$ & $\begin{array}{l}0.56 \\
* * *\end{array}$ & 0.10 & $\begin{array}{l}-0.56 \\
* * *\end{array}$ & 0.02 \\
\hline HI & & & & & $\begin{array}{l}-0.80 \\
* * *\end{array}$ & $\begin{array}{l}-0.61 \\
* * *\end{array}$ & -0.09 & $\begin{array}{l}0.53 \\
* * *\end{array}$ & -0.07 \\
\hline LOF & & & & & & $\begin{array}{l}-0.47 \\
* * *\end{array}$ & -0.07 & $\begin{array}{l}-0.55 \\
* * *\end{array}$ & $\begin{array}{l}0.14 \\
*\end{array}$ \\
\hline MAS & & & & & & & 0.16 & $\begin{array}{l}-0.31 \\
* * *\end{array}$ & $\begin{array}{c}-0.07 \\
*\end{array}$ \\
\hline TGW & & & & & & & & 0.07 & $\underset{* * *}{-0.23}$ \\
\hline YLD & & & & & & & & & $\underset{* * *}{-0.35}$ \\
\hline
\end{tabular}


Table 3 List of 86 putative QTLs for nine traits detected in S42

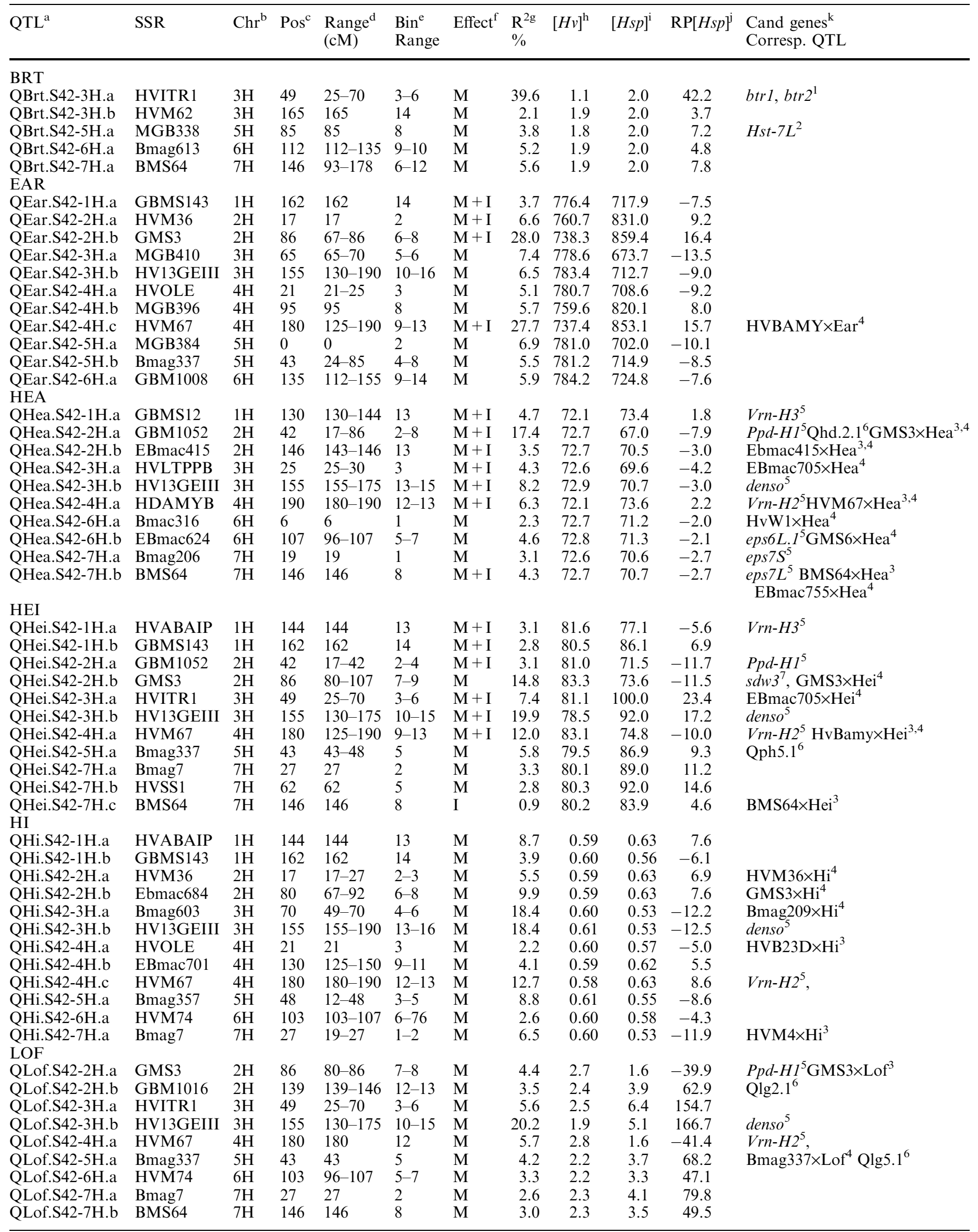


Table 3 (Contd.)

\begin{tabular}{|c|c|c|c|c|c|c|c|c|c|c|c|}
\hline \multicolumn{12}{|l|}{ MAS } \\
\hline QMas.S42-2H.a & GMS3 & $2 \mathrm{H}$ & 86 & $67-107$ & $6-9$ & M & 8.4 & 29.6 & 25.2 & -15.0 & \\
\hline QMas.S42-3H.a & HVM62 & $3 \mathrm{H}$ & 165 & $130-190$ & $10-16$ & M & 9.0 & 27.6 & 33.0 & 19.6 & \\
\hline QMas.S42-4H.a & MGB396 & $4 \mathrm{H}$ & 95 & 95 & 8 & M & 2.8 & 29.0 & 26.2 & -9.8 & Ebmac679 $\times \mathrm{Mas}^{4}$ \\
\hline QMas.S42-4H.b & HVM67 & $4 \mathrm{H}$ & 180 & $170-190$ & $12-13$ & M & 4.9 & 29.5 & 26.2 & -11.1 & \\
\hline QMas.S42-5H.a & Bmag337 & $5 \mathrm{H}$ & 43 & 43 & 5 & M & 6.8 & 27.7 & 32.6 & 17.4 & \\
\hline $\begin{array}{l}\text { QMas.S42-7H.a } \\
\text { TGW }\end{array}$ & Bmag7 & $7 \mathrm{H}$ & 27 & $19-27$ & $1-2$ & M & 4.1 & 28.2 & 34.0 & 20.8 & \\
\hline QTgw.S42-2H.a & GBM1035 & $2 \mathrm{H}$ & 27 & $17-86$ & $2-8$ & M & 7.7 & 42.7 & 44.1 & 3.2 & $\mathrm{GMS} \times \mathrm{Tgw}^{3} \mathrm{HVM} 36 \times \mathrm{Tgw}^{4}$ \\
\hline QTgw.S42-3H.a & HVM60 & $3 \mathrm{H}$ & 110 & $110-130$ & $9-10$ & M & 8.4 & 42.7 & 44.0 & 3.0 & HVM $60 \times \operatorname{Tgw}^{4}$ \\
\hline QTgw.S42-3H.b & MGB358 & $3 \mathrm{H}$ & 175 & $165-175$ & $14-15$ & M & 11.8 & 43.2 & 41.6 & -3.6 & \\
\hline QTgw.S42-4H.a & MGB396 & $4 \mathrm{H}$ & 95 & 95 & 8 & $M+I$ & 10.2 & 43.3 & 41.9 & -3.3 & \\
\hline QTgw.S42-4H.b & EBmac701 & $4 \mathrm{H}$ & 130 & $125-190$ & $9-13$ & $\mathrm{M}$ & 33.6 & 43.5 & 40.9 & -5.9 & HvBAMY $\times \operatorname{Tgw}^{4}$ \\
\hline QTgw.S42-5H.a & MGB357 & $5 \mathrm{H}$ & 165 & 165 & 14 & M & 4.6 & 43.0 & 41.0 & -4.7 & 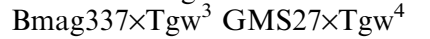 \\
\hline QTgw.S42-6H.a & GBM1049 & $6 \mathrm{H}$ & 40 & 40 & 3 & I & 4.2 & 43.1 & 42.1 & -2.4 & \\
\hline QTgw.S42-6H.b & HVM74 & $6 \mathrm{H}$ & 103 & $96-103$ & $5-6$ & I & 3.6 & 43.1 & 42.3 & -1.9 & Qtgw6.1 ${ }^{6}$ \\
\hline $\begin{array}{l}\text { QTgw.S42-7H.a } \\
\text { YLD }\end{array}$ & BMS64 & $7 \mathrm{H}$ & 146 & $146-181$ & $8-12$ & M & 8.5 & 43.1 & 41.4 & -4.1 & Bmag135 $\times \operatorname{Tgw}^{3}$ \\
\hline QYld.S42-1H.a & Bmag105 & $1 \mathrm{H}$ & 75 & $52-85$ & $6-8$ & M & 6.2 & 60.3 & 49.6 & -17.7 & Qyld.1.1 ${ }^{6}$ \\
\hline QYld.S42-2H.a & GBM1035 & $2 \mathrm{H}$ & 27 & $17-27$ & $2-3$ & $\mathrm{I}$ & 1.0 & 59.1 & 60.4 & 2.3 & Ppd-H1 ${ }^{5}$ Qyld2.1 ${ }^{6}$ HVM36×Yld 4 \\
\hline QYld.S42-2H.b & HVTUB & $2 \mathrm{H}$ & 92 & $86-92$ & 8 & I & 1.7 & 59.0 & 60.2 & 2.0 & GMS3 $\times$ Yld $^{4}$ \\
\hline QYld.S42-2H.c & GBM1016 & $2 \mathrm{H}$ & 139 & $122-146$ & $10-13$ & M & 3.3 & 60.0 & 51.0 & -15.0 & HVM $54 \times$ Yld $^{3}$ \\
\hline QYld.S42-3H.a & HVLTPPB & $3 \mathrm{H}$ & 25 & $25-70$ & $3-6$ & $\mathrm{M}+\mathrm{I}$ & 13.7 & 60.2 & 39.9 & -33.7 & btr 1, btr $2^{1}$ \\
\hline QYld.S42-3H.b & HV13GEIII & $3 \mathrm{H}$ & 155 & $155-175$ & $13-15$ & $\mathrm{M}+\mathrm{I}$ & 9.8 & 60.9 & 51.9 & -14.8 & denso ${ }^{5}$ Qyld.3.1 $1^{6}$ \\
\hline QYld.S42-4H.a & GBM1015 & $4 \mathrm{H}$ & 170 & $125-190$ & $9-13$ & $M+I$ & 3.1 & 58.4 & 62.5 & 7.1 & EBmac679×Yld ${ }^{4}$ \\
\hline QYld.S42-5H.a & Bmag337 & $5 \mathrm{H}$ & 43 & 43 & 5 & M & 4.4 & 60.3 & 54.0 & -10.4 & \\
\hline QYld.S42-5H.b & MGB338 & $5 \mathrm{H}$ & 85 & 85 & 8 & M & 2.1 & 60.1 & 53.9 & -10.2 & HvUDPGPP $\times Y_{1 d}{ }^{4}$ \\
\hline QYld.S42-5H.c & AF04394A & $5 \mathrm{H}$ & 137 & $126-137$ & $10-11$ & M & 3.1 & 60.2 & 53.5 & -11.2 & GMS27×Y1d 3,4 \\
\hline QYld.S42-6H.a & Bmag613 & $6 \mathrm{H}$ & 112 & $96-112$ & $5-9$ & M & 4.9 & 60.7 & 55.4 & -8.7 & \\
\hline QYld.S42-7H.a & Bmag7 & $7 \mathrm{H}$ & 27 & 27 & 2 & M & 2.2 & 60.0 & 52.8 & -12.0 & \\
\hline QYld.S42-7H.b & BMS64 & $7 \mathrm{H}$ & 146 & 146 & 8 & M & 4.0 & 60.2 & 53.2 & -11.6 & EBmac755×Yld ${ }^{3}$ \\
\hline
\end{tabular}

"QTL names consist of the qualifier "Q", the trait abbreviation, the population name, the chromosomal location and a consecutive character to discriminate two or more QTLs per chromosome. Linked significant markers ( $\leq 20 \mathrm{cM}$ ) were interpreted as one QTL.

${ }^{\mathrm{b}}$ Chromosomal localisation of the marker

${ }^{c}$ Position of the listed SSR marker in cM taken from von Korff et al. (2004)

${ }^{\mathrm{d}}$ CentiMorgan range from the first to the last significant marker in a group

e Genotyped markers were assigned to bins according to information by Kleinhofs and Graner (2001) and the OWB mapping population (Costa et al. 2001, http://www.barleyworld.org). If several linked markers are significant, the bin range is given

${ }^{\mathrm{f}}$ A putative QTL was assumed in the vicinity of a marker locus, if the marker main effect $(\mathrm{M})$ or the $\mathrm{M} \times \mathrm{E}$ interaction (I) was significant in the 3-factorial ANOVA with $P<0.01$

${ }^{\mathrm{g}} \mathrm{R}_{\mathrm{M}}^{2}$ and $\mathrm{R}_{(\mathrm{M} \times \mathrm{E})}^{2}$ : Proportion of the genetic variance, which is explained by the marker main effect (if Effect contains ' $M$ ') or explained by the $\mathrm{M} \times \mathrm{E}$ interaction effect (if Effect $=$ 'I'), respectively.

${ }_{\mathrm{h}}$ Least square means of trait value across all tested environments for $\mathrm{BC}_{2} \mathrm{DH}$ lines carrying the elite genotype $(H v)$ at the given marker locus

${ }^{\mathrm{i}}$ Least square means of trait value across all tested environments for $\mathrm{BC}_{2} \mathrm{DH}$ lines carrying the exotic genotype (Hsp) at the given SSR marker locus

${ }^{\mathrm{j}}$ Relative performance: $\left.(H s p-H v) \times 100 / H v\right)$, where $H v$ and $H s p$ are the least square means of lines with the elite and exotic genotype, respectively, at the given SSR marker locus

${ }^{\mathrm{k}}$ Candidate genes or corresponding QTLs published in: 1 Franckowiak (1997), 2 Kandemir et al. (2000), 3 Pillen et al. (2003), 4 Pillen et al. (2004), 5 Laurie et al. (1995), 6 Li et al. (2004), 7 Gottwald et al. (2004). At underlined QTLs, the exotic allele showed the same qualitative effect as in this study.

were significant. The exotic genotype improved the trait performance at $31(36.0 \%)$ of 86 QTLs. In the following, the QTLs are presented for each trait separately.

\section{Brittleness (BRT)}

For BRT, the analysis revealed five QTLs with marker main effects located on chromosomes $3 \mathrm{H}, 5 \mathrm{H}, 6 \mathrm{H}$ and $7 \mathrm{H}$. The exotic allele was responsible for brittleness at all detected QTLs. The QTL QBrt.S42-3H.a exerted the strongest effect on brittleness. This QTL explained $39.6 \%$ of the genetic variance and the exotic allele at this locus increased BRT by $42.2 \%$ relative to the elite genotype.

\section{Ears per $\mathrm{m}^{2}$ (EAR)}

For EAR, eleven QTLs with a marker main effect were detected on all chromosomes with the exception of $7 \mathrm{H}$. At four loci the marker main effect and the $\mathrm{M} \times \mathrm{E}$ interaction effect were significant. At four QTLs the exotic allele increased EAR by up to $16.4 \%$ at QEar.S42-2H.b. The latter QTL explained $28.0 \%$ of the genetic variance. At the remaining QTLs, the exotic 


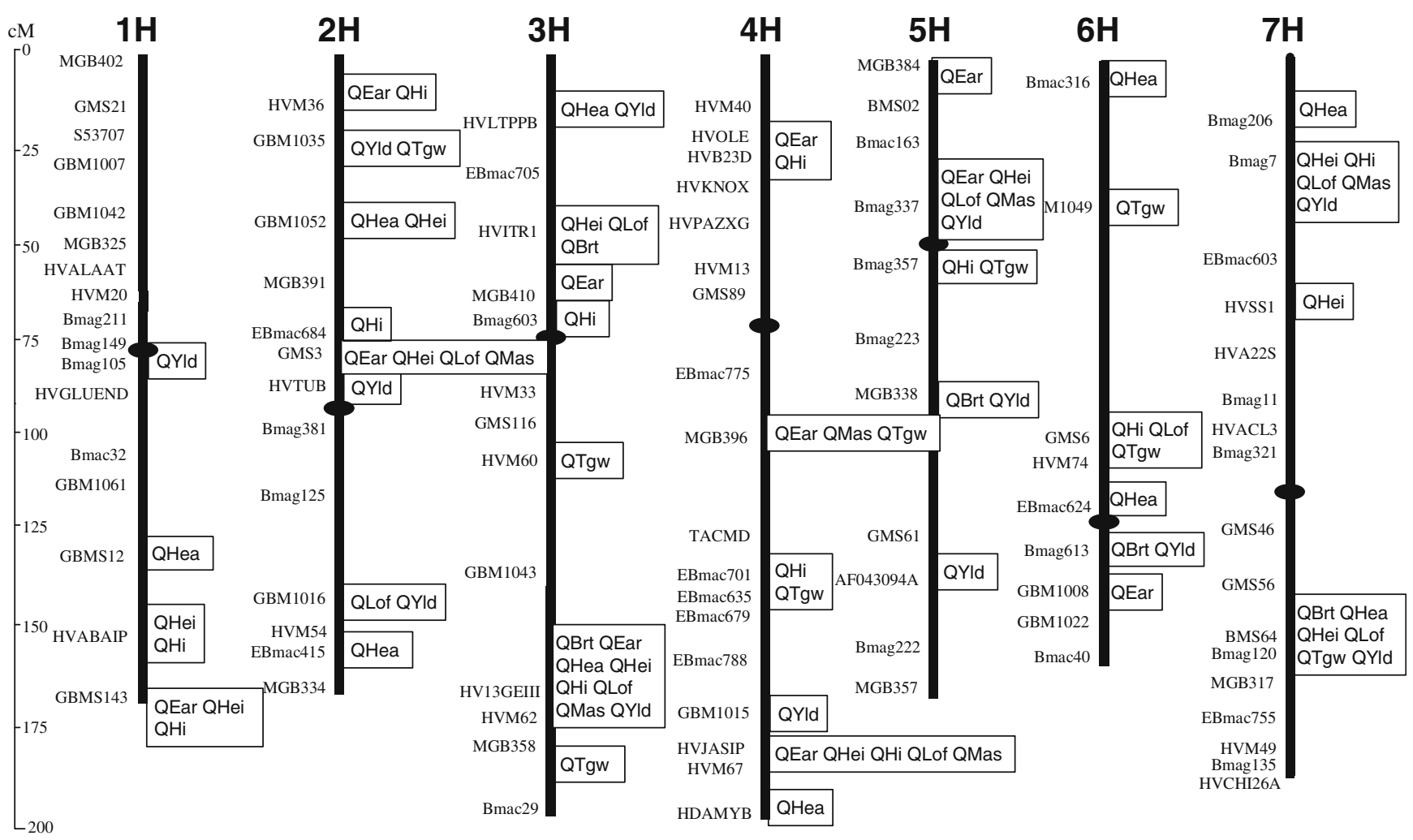

Fig. 1 QTL map of the population S42 showing 86 putative QTLs detected for nine agronomic traits. The putative QTLs are indicated to the right of the SSR marker, which showed the

highest $F$-value of a group of linked significant markers (see Table 3). Trait abbreviations of QTLs follows Table 1 allele was associated with a reduced number of EAR of up to $13.5 \%$ at QEar.S42-2H.c.

Days until heading (HEA)

Ten QTLs for HEA were located on all chromosomes with the exception of chromosome $5 \mathrm{H}$. All loci revealed a significant marker main effect, while seven loci exhibited in addition a significant $\mathrm{M} \times \mathrm{E}$ interaction effect. At eight QTLs the exotic allele reduced the number of days until heading. At the QTL QHea.S42-2H.a, explaining $17.4 \%$ of the genetic variance, the exotic allele was associated with a reduced heading time of $7.9 \%$.

\section{Plant height (HEI)}

Eleven QTLs were detected for HEI. Six of the ten QTLs with marker main effect also exhibited an $\mathrm{M} \times \mathrm{E}$ interaction effect. At one QTL only the $M \times E$ interaction effect was significant. At four QTLs the exotic allele displayed a desirable decrease in plant height of up to 11.7\% (QHei.S42-2H.a). At seven QTLs the exotic allele increased plant height by up to $23.4 \%$ (QHei.S42-3H.a). A maximum of explained genetic variance was found at QHei.S42-3H.b (19.9\%).
Harvest index (HI)

For HI, twelve QTLs with a marker main effect were identified on all seven chromosomes. At five loci the exotic allele increased HI by up to $8.6 \%$ (QHi.S42.4H.c). At seven QTLs, the exotic allele decreased HI. The strongest QTLs, QHi.S42.3H.a and QHi.S42.3H.b, explained $18.4 \%$ of the genetic variance each and reduced HI by $12.2 \%$ and $12.5 \%$, respectively.

\section{Lodging at flowering (LOF)}

Nine QTLs with a marker main effect were detected for LOF on chromosomes $2 \mathrm{H}$ to $7 \mathrm{H}$. At two QTLs, QLof.S42-2H.a and QLof.S42-4H.a, which explained $4.4 \%$ and $5.7 \%$ of the genetic variance, the exotic allele reduced lodging by $39.9 \%$ and $41.4 \%$, respectively. At the remaining QTLs the exotic allele increased lodging by up to $166.7 \%$ (QLof.S42-3H.b).

Vegetative dry biomass (MAS)

For the trait MAS, six QTLs with marker main effects were detected on chromosomes $2 \mathrm{H}$ to $5 \mathrm{H}$ and $7 \mathrm{H}$. At three QTLs the exotic allele increased MAS by up to 
$20.8 \%$ at QMas.S42-7H.a. A maximum of explained genetic variance was found at QMas.S42-3H.a (9.0\%).

\section{Thousand grain weight (TGW)}

Nine QTLs were detected for TGW and located on chromosomes $2 \mathrm{H}$ to $7 \mathrm{H}$. For seven QTLs the marker main effect, for two QTLs only the $M \times E$ interaction effect and for one QTL both effects were significant. At two QTLs, QTgw.S42.2H.a and QTgw.S42-3H.a, the exotic allele increased $\mathrm{TGW}$ by $3.2 \%$ and $3.0 \%$, respectively. At the remaining QTLs the exotic allele reduced TGW. A maximum of explained genetic variance was found at QTgw.S42-4H.b (33.6\%).

\section{Yield (YLD)}

Altogether 13 QTLs for yield were located on all seven chromosomes. Eleven loci exhibited a significant marker main effect, two loci a significant $\mathrm{M} \times \mathrm{E}$ interaction and three loci both, a marker main and a $\mathrm{M} \times \mathrm{E}$ interaction effect. The exotic allele increased yield at three QTLs by up to $7.1 \%$ (QYld.S42-4H.a). At the majority of QTLs the exotic allele reduced grain yield by up to $33.7 \%$ (QYld.S42-3H.a). A maximum of explained genetic variance was found at QYld.S42-3H.a (13.7\%).

\section{Discussion}

QTL analysis: statistical model

The QTL model used in this study accounted for $M \times E$ interaction and thereby provided a test for estimates regarding the relative importance of the QTL by environment interaction in the total genetic variation. According to Haldane (1947) genotype environment interactions have only important implications for marker assisted selection if genotypes switch ranks from one environment to another. In this study, several $M \times E$ interactions were obviously crossover interactions, with favourable effects of the exotic allele in some environments, but negative effects in other environments (indicated with 'I' in Table 2). However, the majority of $M \times E$ interaction effects $(80.7 \%)$, coincided with marker main effects (' $M+I$ ' in Table 2 ) and were only due to changes in the magnitude of the effects. These QTLs may, therefore, still be used for marker assisted selection across environments. Compared to Pillen et al. (2003 and 2004), the factor $\mathrm{BC}_{2} \mathrm{DH}$ line nested in the marker genotype was included into the model. This factor accounted for the variation within the two genotype classes at a marker locus due to the presence of additional introgressions in the $\mathrm{BC}_{2} \mathrm{DH}$ lines. The inclusion of this additional factor allowed us, thus, to reduce the residual variance in the ANOVA and to increase the power of QTL detection.
QTL analysis: comparison with candidate genes and other QTL analyses in barley

The results of the present QTL analysis in S42 were compared with studies of candidate genes in barley and three AB-QTL analyses carried out in barley by Pillen et al. (2003, 2004) and Li et al. (2004). Pillen et al. (2003, 2004) conducted two separate AB-QTL analyses to assess agronomic performance in two $\mathrm{BC}_{2} \mathrm{~F}_{2}$ populations 'A101' and 'H101' derived from crosses between the wild barley accession ISR101-23 with the feeding barley cultivars Apex (A) and Harry $(\mathrm{H})$, respectively. Li et al. (2004) conducted an AB-QTL analysis in a $\mathrm{BC}_{3} \mathrm{DH}$ population derived from the spring barley cultivar Brenda and the exotic accession HS213. For 48 of 86 QTLs detected in this study, at least one corresponding quantitative or qualitative locus from the literature was recorded (Table 3). Although the donor and recipient germplasm differed between the present and the above mentioned AB-QTL studies, the exotic alleles exhibited the same qualitative effect at 31 out of $43(72.1 \%)$ corresponding QTL locations. The exotic alleles are thus often similar in their effects and clearly different from the elite alleles. The effectiveness of the exotic introgressions in different genetic backgrounds gives a first indication that alleles from these donors might not yet be present in adapted germplasm.

The QTLs for different traits were often mapped on the same or adjacent locations, forming several clusters (Figure 1). The strong effects of exotic introgressions on chromosome $2 \mathrm{H}$ on almost all analysed quantitative traits was also found by Pillen et al. $(2003,2004)$ and Li et al. (2004). And at the QTL on chromosome 4H the exotic allele increased EAR, HI and YLD and decreased HEI, LOF, MAS and TGW. These findings were in agreement with the reported positive correlations between EAR, HI and YLD and the negative correlation of EAR with HEI. In the following, the QTL results for the analysed traits will be discussed separately.

\section{Brittleness}

Wild barley carries two complementary and dominant genes on chromosome $3 \mathrm{H}, B \operatorname{trl}$ and Btr2, for the formation of a brittle rachis, whereas cultivated barley carries recessive alleles at either of the loci, resulting in a non-brittle rachis (Franckowiak 1997). We detected a corresponding major QTL (QBrt.S42-3H.a) on the short arm of chromosome $3 \mathrm{H}$, albeit spanning $45 \mathrm{cM}$. This QTL explained $39.6 \%$ of the genetic variance, while the remaining loci had minor effects on brittleness. Indeed, several studies have reported segregation ratios for brittleness, which do not fit the two complementary gene models, but suggested the presence of additional loci (Matus et al. 2003). Komatsuda et al. (2004) detected two minor QTLs for brittleness on chromosomes $5 \mathrm{H}$ and $7 \mathrm{H}$ coinciding with the position of the QTLs QBrt.S42-5H.a and QBrt.S42-7H.a. The QTL on 
chromosome $5 \mathrm{H}$ may also be identical to the weak rachis QTL Hst-7L detected by Kandemir et al. (2000).

\section{Time to heading}

Wild barley is characterised by early and heterogeneous flowering, presumably as an adaptation strategy to drought prone environments. Indeed, in the majority of QTLs in S42, the exotic allele decreased time to heading. The QTL QHea.S42-2H.a, explaining 17.4\% of the genetic variance, coincides with the major flowering QTL on chromosome arm 2HS detected by Pillen et al. (2003) and $\mathrm{Li}$ et al. (2004). The same region harbours the photoperiod response gene $\mathrm{Ppd}-\mathrm{Hl}$, which promotes early flowering under long day conditions (Laurie et al. 1995). The QTLs QHea.S42-1H.a and QHea.S42-4H.a mapped to the same location as the vernalisation response genes $\mathrm{Vrn}-\mathrm{H} 3$ and $\mathrm{Vrn}-\mathrm{H} 2$ on chromosomes $1 \mathrm{H}$ and $4 \mathrm{H}$, respectively (Laurie et al. 1995). It is interesting to note, that at these two QTLs, which coincide with known vernalisation response genes, the elite alleles reduced time to heading compared to the exotic alleles. Although vernalisation response is commonly displayed by winter forms of cereals, our data indicate, that vernalisation response may have also been selected in German spring barley cultivars as an adaptation to low temperatures at the beginning of the vegetation period. The QTL QHea.S42-3H.b mapped close to the denso gene, which is known to be associated with a delay in flowering time (Barua et al. 1993; Laurie et al. 1995). The elite parent Scarlett carries the denso gene and as such contributed the allele, which delayed time to heading. Laurie et al. (1995) mapped a number of flowering QTLs termed earliness per se (eps) QTLs, which act independently from environmental cues. In S42, three QTLs on chromosomes $6 \mathrm{H}$ and $7 \mathrm{H}$ could be identified which correspond to the genes eps6L.1, eps $7 S$ and eps $7 L$ (see Table 3).

\section{Plant height and lodging}

The majority of QTLs for lodging coincided with QTLs for plant height according to the strong positive correlation found between plant height and lodging. The QTLs QLof.S42-2H.a and QHei.S42-2H.b, located on the short arm of chromosome $2 \mathrm{H}$, for example, reduced lodging by $39.9 \%$ and plant height by $11.5 \%$. A corresponding candidate gene for QHei.S42-2H.b is the dwarfing gene $s d w 3$ which has been mapped by Gottwald et al. (2004). This gene conveys insensitivity to gibberellic acid and might be homoeologous to the Rht series of dwarfing genes in wheat (Börner et al. 1998). Further upstream on the short arm of chromosome $2 \mathrm{H}$, Laurie et al. (1994) mapped the Ppd-HI gene in the Igri $\times$ Triumph $\mathrm{DH}$ population and reported a strong pleiotropic effect of the region on plant height. The $P p d-$ $\mathrm{Hl}$ gene is thus a candidate gene for the corresponding
QTL QHei.S42-2H.a. The QTL QHei.S42-3H.b, which coincides with the strongest QTL for lodging (QLof.S423 H.b), maps to the same genomic region as the dwarfing gene denso. It has been shown that this gene, which is present in Scarlett, reduces height and lodging (Bezant et al. 1996; Yin et al. 1999). The genomic region on $4 \mathrm{H}$ affecting plant height and lodging also exerted a significant effect on height in the populations A101 and H101 (Pillen et al. 2003, 2004). The exotic allele reduced height in the present study by $10.0 \%$ in S42 and by 10.4 and $5.9 \%$ in A101 and H101, respectively.

\section{Yield}

The majority of QTLs analyses for yield and yield component traits in barley were conducted with early balanced populations (Hayes et al. 1993, 1996, Thomas et al. 1995; Tinker et al. 1996; Bezant et al. 1997, Yin et al. 1999, 2002, Marquez-Cedillo 2000), while only four QTLs analyses have so far been conducted in advanced backcross barley populations (Matus et al. 2003; Pillen et al. 2003, 2004, Li et al. 2004). Some QTLs in classical QTL studies consistently mapped to the same genomic regions despite a wide range of different germplasms used. These are predominantly yield QTLs identified on chromosome arms $2 \mathrm{HS}, 3 \mathrm{HL}$ and $6 \mathrm{HL}$. Their effect on yield are commonly explained by pleiotropic effects of the photoperiod response gene Ppd-HI on $2 \mathrm{HS}$ (Li et al. 2004), the dwarfing gene denso on $3 \mathrm{HL}$ (Thomas et al. 1995), and linkage to the Amyl locus on 6HL (Powell et al. 1990; Bezant et al. 1997). These genomic regions also revealed significant effects on yield in this study (QYld.S42-2H.a, QYld.S42-3H.b and QYld.S42-6H.a) with the favourable QTL allele contributed by the elite parent. Other yield QTLs detected in this study obviously did not coincide with yield QTLs identified in classical QTL studies. The QTL QYld.S42$3 \mathrm{H} . \mathrm{a}$, where the exotic allele reduced yield by $33.7 \%$, coincided with the major QTL for brittleness (QBrt.S42$3 \mathrm{H} . \mathrm{a})$ and the candidate genes btr 1 and btr2 on the short arm of chromosome $3 \mathrm{H}$. Further yield QTLs on chromosomes 3H (QYld.S42-3H.b), 5H (QYld.S42-5H.b), 6H (QYld.S42-6H.a) and 7H (QYld.S42-7H.b), mapped to corresponding QTLs identified for brittleness. The negative effect of these exotic QTL alleles on yield may, therefore, be due to exotic alleles coding for brittleness.

A maximum yield increase of $7.1 \%$ due to the presence of an exotic allele was recorded at the QTL QYld.S42-4H.a on chromosome 4H. Interestingly, a comparison with other AB-QTL analyses revealed that the QTLs with the strongest favourable effect of the exotic allele detected in the populations A101 and H101 (Pillen et al. 2003, 2004) also mapped to chromosome $4 \mathrm{H}$. Here, it is worthwhile to point out that the exotic accession ISR101-23 used by the above mentioned studies was also collected from Israel. Pillen et al. (2000), however, demonstrated that ISR101-23 was genetically different from ISR42-8 based on SSR marker 
data. In addition, fragment lengths scored for all SSR markers on 4H differed between ISR42-8 and ISR101-23 (data not shown). Further concordances of QTL positions with yield QTLs detected by Li et al. (2004) and Pillen et al. (2003, 2004) were found on chromosome arms $1 \mathrm{HS}, 2 \mathrm{HL}, 5 \mathrm{HL}$ and $7 \mathrm{HL}$. In all cases, negative effects of the exotic allele were recorded. In addition, $\mathrm{Li}$ et al. (2004) detected a yield QTL on chromosome $3 \mathrm{H}$ coinciding with the QTL QYld.S42-3H.b.

\section{Yield components}

In this study, the yield components ears per $\mathrm{m}^{2}$ and thousand grain weight were analysed next to harvest index and vegetative biomass. Yield components generally show negative correlations, as it was also detected in this study, where EAR and TGW exhibited a negative correlation of -0.21 (Table 2). For the manipulation of yield it is particularly interesting to find alleles, which break these genetic correlations. Indeed, the exotic alleles on the short arm of chromosome $2 \mathrm{H}$ revealed positive effects on EAR (QEar.S42-2H.a and QEar.S422H.b) and TGW (QTgw.S42-2H.a) which also resulted in a significant yield increase (QYld.S42-2H.a and QYld.S42-2H.b). A second coincidence of QTLs can be found on chromosome $4 \mathrm{H}$. Here, the favourable effect of the exotic alleles on EAR (QEar.S42-4H.c) and YLD (QYld.S42-4H.a) was coupled with a negative effect on TGW (QTgw.S42-4H.b). Reciprocal effects, however, may also arise when trait values are indirectly inferred. This holds true for the trait HI, which was inferred from the traits MAS and single plant yield. Accordingly, QTLs detected for MAS on chromosomes $2 \mathrm{H}, 3 \mathrm{H}, 4 \mathrm{H}$ and $7 \mathrm{H}$ were also significant for $\mathrm{HI}$ but exhibited opposing effects on both traits.

The present study has demonstrated that wild barley does harbour favourable alleles, which have the potential to improve quantitative agronomic traits and can enrich the genetic basis of cultivated barley. In this study, exotic alleles with a favourable effect on yield and yield component traits were detected, in particular on the short arm of chromosome $2 \mathrm{H}$ and the long arm of chromosome $4 \mathrm{H}$. Exotic alleles on chromosome $2 \mathrm{H}$ improved the performance of the traits EAR, HEA, HEI, HI, LOF, TGW and YLD. Similarly, exotic alleles on chromosome $4 \mathrm{H}$ exhibited favourable effects on EAR, HEI, HI, LOF and YLD. In future, the effects of the favourable exotic alleles at the two genomic regions on $2 \mathrm{H}$ and $4 \mathrm{H}$ are of particular interest and will be verified (1) in a second $A B$ population derived from the same donor accession and (2) in near-isogenic lines (NILs). The identification of markers linked to the favourable QTL alleles as well as the advanced backcross population structure employed in this study will allow us to rapidly isolate these QTLs in NILs. Markers closely linked to the QTLs can be used to select against deleterious wild characters, like brittleness, and to select lines carrying the favourable alleles using marker assisted selection. In addition, pure introgression lines (ILs) are currently generated from pre-selected candidate lines of the population S42 (von Korff et al. 2004). In future, these ILs will be exploited in order to verify the QTL effects and to systematically study the molecular basis of these QTLs.

Acknowledgements We thank Dr. Eberhard Laubach (Nordsaat Saatzucht), Dr. Claus Einfeldt (Saatzucht Dr. J. Ackermann), Mr. Josef Breun (Saatzucht Josef Breun) and their teams for conducting the field experiments. The excellent technical assistance of Merle Noschinski, Carsten Golletz, and the team of our experimental station Dikopshof in Wesseling is appreciated. This work was funded by the German Plant Genome Research Initiative (GABI) of the Federal Ministry of Education and Research (BMBF, project 0312278A).

\section{References}

Backes G, Madsen LH, Jaiser H, Stougaard J, Herz M, Mohler V, Jahoor A (2003) Localization of genes for resistance against Blumeria graminis f. sp. hordei and Puccinia graminis in a cross between a barley cultivar and a wild barley (Hordeum vulgare ssp. spontaneum) line. Theor Appl Genet 106:353-362

Baek HJ, Beharav A, Nevo E (2003) Ecological-genomic diversity of microsatellites in wild barley, Hordeum spontaneum, populations in Jordan. Theor Appl Genet 106:397-410

Barua UM, Chalmers KJ, Hackett CA, Thomas WTB, Powell W, Waugh R (1993) Identification of RAPD markers linked to a Rhynchosporium secalis resistance locus in barley using nearisogenic lines and bulked segregant analysis. Heredity 71:177184

Bernacchi D, Beck-Bunn D, Eshed T, Lopez Y, Petiard V, Uhlig J, Zamir D, Tanksley SD (1998) Advanced backcross QTL analysis in tomato. I. Identification of QTLs for traits of agronomic importance from Lycopersicon hirsutum. Theor Appl Genet 97:381-397

Bezant JH, Laurie DA, Pratchett N, Chojecki J, Kearsey MJ (1996) Marker regression mapping of QTL controlling flowering time and plant height in a spring barley (Hordeum vulgare L.) cross. Heredity 77:64-71

Bezant J, Pratchett N, Laurie D, Chojeki J, Kearsey M (1997) Mapping QTL controlling yield and yield components in a spring barley (Hordeum vulgare L.) cross using marker regression. Mol Breeding 3:29-38

Börner A, Korzun V, Worland AJ (1998) Comparative genetic mapping of loci affecting plant height and development in cereals. Euphytica 100:245-248

Brondani C, Rangel PHN, Brondani RPV, Ferreira ME (2002) QTL mapping and introgression of yield-related traits from Oryza glumaepatula to cultivated rice (Oryza sativa) using microsatellite markers. Theor Appl Genet 104:1192-1203

Costa JM, Corey A, Hayes PM, Jobet C, Kleinhofs A, KopischObusch A, Kramer SF, Kudrna D, Li M, Riera-Lizarazu O, Sato K, Szucs P, Toojinda T, Vales MJ, Wolfe RI (2001) Molecular mapping of the Oregon Wolfe Barleys: a phenotypically polymorphic doubled-haploid population. Theor Appl Genet 103:415-424

Erkkilä MJ, Leah R, Ahokas H, Cameron-Mills V (1998) Alleledependent barley grain $\beta$-amylase activity. Plant Physiol 117:679-685

Fischbeck G, Jahoor A (1991) The transfer of genes for mildew resistance from Hordeum spontaneum. In: Jorgensen JH (ed) Integrated control of cereal mildews: virulence patterns and their change. Riso National Laboratory, Denmark, pp 247-255

Franckowiak JD (1997) Revised linkage maps for morphological markers in barley, Hordeum vulgare. Barley Genet Newsl 26:9-21 
Fulton TM, Nelson JC, Tanksley SD (1997) Introgression and DNA marker analysis of Lycopersicon peruvianum, a wild relative of the cultivated tomato, into Lycopersicon esculentum, followed through three successive backcross generations. Theor Appl Genet 95:895-902

Fulton TM, Grandillo S, Beck-Bunn T, Fridman E, Frampton A, Lopez J, Petiard V, Uhlig J, Zamir D, Tanksley SD (2000) Advanced backcross QTL analysis of a Lycopersicon esculentum $\times$ Lycopersicon parviflorum cross. Theor Appl Genet 100:1025-1042

Fulton TM, Bucheli P, Voirol E, Lopez J, Pétiard V, Tanksley SD (2002) Quantitative trait loci (QTL) affecting sugars, organic acids and other biochemical properties possibly contributing to flavor, identified in four advanced backcross populations of tomato. Euphytica 127:163-177

Gottwald S, Börner A, Stein N, Sasaki T, Graner A (2004) The gibberellic-acid insensitive dwarfing gene $s d w 3$ of barley is located on chromosome $2 \mathrm{HS}$ in a region that shows high colinearity with rice chromosome 7L. Mol Gen Genomics 271:426-436

Gur A, Zamir D (2004) Unused natural variation can lift yield barriers in plant breeding. PLOS Biol 2 (10):1610-1615

Haldane JBS (1947) The interaction of nature and nurture. Annals of Eugenics 13:197-205

Hayes PM, Liu BH, Knapp SJ, Chen F, Jones B, Blake T, Franckowiak J, Rasmusson D, Sorrells M, Ullrich SE, Wesenberg D, Kleinhofs A (1993) Quantitative trait locus effects and environmental interaction in a sample of North American barley germplasm. Theor Appl Genet 87:392-401

Hayes PM, Chen FQ, Kleinhofs A, Kilian A, Mather D (1996) Barley genome mapping and its applications. In: Jauhar PP (ed) Methods of Genome Analysis in Plants. CRC Press, Boca Raton, pp 229-249

Ho JC, McCouch SR, Smith ME (2002) Improvement of hybrid yield by advanced backcross QTL analysis in maize. Theor Appl Genet 105:440-448

Huang XQ, Cöster H, Ganal MW, Röder MS (2003) Advanced backcross QTL analysis for the identification of quantitative trait loci alleles from wild relatives of wheat (Triticum aestivum L.). Theor Appl Genet 106:1379-89

Huang XQ, Kempf H, Ganal MW, Röder MS (2004) Advanced backcross QTL analysis in progenies derived from a cross between a German elite winter wheat variety and a synthetic wheat (Triticum aestivum L.). Theor Appl Genet 109:933-43

Jefferies SP, Barr AR, Karakousis A, Kretschmer JM, Manning S, Chalmers KJ, Nelson JC, Islam AKMR, Langridge P (1999) Mapping of chromosome regions conferring boron toxicity tolerance in barley (Hordeum vulgare L.). Theor Appl Genet 98:1293-1303

Kandemir N, Kudrna DA, Ullrich SE, Kleinhofs A (2000) Molecular marker assisted genetic analysis of head shattering in six-rowed barley. Theor Appl Genet 101:203-210

Kleinhofs A, Graner A (2001) An integrated map of the barley genome. Kluwer, Dordrecht, The Netherlands, pp 187-99

Komatsuda T, Maxim P, Senthil N, Mano Y (2004) High-density AFLP map of nonbrittle rachis 1 (btrl) and 2 (btr2) genes in barley (Hordeum vulgare L.). Theor Appl Genet 109:986-995

von Korff M, Wang H, Léon J, Pillen K (2004) Development of candidate introgression lines using an exotic barley accession (H. vulgare ssp. spontaneum) as donor. Theor Appl Genet 109:1736-45

von Korff M, Wang H, Léon J, Pillen K (2005) AB-QTL analysis in spring barley: I. Detection of resistance genes against powdery mildew, leaf rust and scald introgressed from wild barley. Theor Appl Genet (in press)

Laurie DA, Pratchett N, Bezant JH, Snape JW (1994) Genetic analysis of a photoperiod-response gene on the short arm of chromosome $2(2 \mathrm{H})$ of Hordeum vulgare (barley). Heredity 72:619-627

Laurie DA, Pratchett N, Bezant JH, Snape JW (1995) RFLP mapping of five major genes and eight quantitative trait loci controlling flowering time in a winter $\times$ spring barley (Hordeum vulgare L.) cross. Genome 38:575-585
Li JZ, Huang XQ, Heinrichs F, Ganal MW, Röder MS (2004) Analysis of QTLs for yield, yield components, and malting quality in a $\mathrm{BC}_{3}-\mathrm{DH}$ population of spring barley. Theor Appl Genet DOI10.1007/s00122-004-1847-x

Marquez-Cedillo LA, Hayes PM, Jones BL, Kleinhofs A, Legge WG, Rossnagel BG, Sato K, Ullrich E, Wesenberg DM (2000) QTL analysis of malting quality in barley based on the doubledhaploid progeny of two elite North American varieties representing different germplasm groups. Theor Appl Genet 1001:173-184

Matus I, Corey A, Filchkin T, Hayes PM, Vales MI, Kling J, Riera-Lizarazu O, Sato K, Powell W, Waugh R (2003) Development and characterization of recombinant chromosome substitution lines (RCSLs) using Hordeum vulgare subsp. spontaneum as a source of donor alleles in a Hordeum vulgare subsp. vulgare background. Genome 46:1010-1023

Moncada PP, Martinez CP, Borrero J, Chatel M, Gauch H Jr, Guimaraes E, Tohme J, McCouch SR (2001) Quantitative trait loci for yield and yield components in an Oryza sativa $\times$ Oryza rufipogon $\mathrm{BC} 2 \mathrm{~F} 2$ population evaluated in an upland environment. Theor Appl Genet 102:41-52

Pillen K, Binder A, Kreuzkam B, Ramsay L, Waugh R, Förster J, Léon J (2000) Mapping new EMBL-derived barley microsatellites and their use in differentiating German barley cultivars. Theor Appl Genet 101:652-660

Pillen K, Zacharias A, Léon J (2003) Advanced backcross QTL analysis in barley (Hordeum vulgare L.). Theor Appl Genet 107:340-352

Pillen K, Zacharias A, Léon J (2004) Comparative AB-QTL analysis in barley using a single exotic donor of Hordeum vulgare ssp. spontaneum. Theor Appl Genet 108:1591-1601

Powell W, Ellis RP, Macaulay M, McNicol J, Forster BP (1990) The effect of selection for protein and isozyme loci on quantitative traits in a doubled haploid population of barley. Heredity 65:115-122

Rao GU, Ben Chaim A, Borovsky Y, Paran I (2003) Mapping of yield related QTLs in pepper in an interspecific cross of Capsicum annuum and C. frutescens. Theor Appl Genet 106:1457-1466

SAS Institute (2003) The SAS system for Windows, release 9.1. SAS Institute, Cary, N.C. USA

Septiningsih EM, Praseiyono J, Lubis E, Tai TH, Tjubaryat T, Moeljopawiro S, McCouch SR (2003) Identification of quantitative trait loci for yield and yield components in an advanced backcross population derived from the Oryza sativa variety IR64 and the wild relative O. rufipogon. Theor Appl Genet 107:1419-32

Tanksley SD, Nelson JC (1996) Advanced backcross QTL analysis: a method of the simultaneous discovery and transfer of valuable QTLs from unadapted germplasm into elite breeding lines. Theor Appl Genet 92:191-203

Tanksley SD, Grandillo S, Fulton TM, Zamir D, Eshed Y, Petiard V, Lopez J, Beck-Brunn T (1996) Advanced backcross QTL analysis in a cross between an elite processing line of tomato and its wild relative L. pimpinellifolium. Theor Appl Genet 92:213-224

Thomas WTB, Powell W, Waugh R, Chalmers KJ, Barua UM, Jack P, Lea V, Forster BP, Swanston JS, Ellis RP, Hanson PR (1995) Detection of quantitative trait loci for agronomic, yield, grain, and disease characters in spring barley (Hordeum vulgare L). Theor Appl Genet 91:1037-1047

Tinker NA, Mather DE, Rossnagel BG, Kasha KJ, Kleinhofs A, Hayes PM, Falk DE, Ferguson T, Shugar LP, Legge WG, Irvine RB, Choo TM, Briggs KG, Ullrich SE, Franckowiak JD, Blake TK, Raf RJ, Dofing SM, Saghai Maroof MA, Scoles GJ, Hoffman D, Dahleen LS, Kilian A, Chen F, Biyashev RM, Kudrna DA, Steffenson BJ (1996) Regions of the genome that affect agronomic performance in two-row barley. Crop Sci 36:1053-1062

Turpeinen T, Tenhola T, Manninen O, Nevo E, Nissila E (2001) Microsatellite diversity associated with ecology factors in Hordeum spontaneum populations in Israel. Mol Ecol 10:15771591 
Wu J-L, Sinha PK, Variar M, Zheng K-L, Leach JE, Courtois B, Leung H (2004) Association between molecular markers and blast resistance in an advanced backcross population of rice. Theor Appl Genet 108:1024-1032

Xiao J, Grandillo S, Ahn SN, McCouch SR, Tanksley SD, Li J, Yuan L (1996) Genes from wild rice improve yield. Nature 384:223-24

Xiao J, Li J, Grandillo S, Nag SN, Yuan L, Tanksley SD, McCouch SR (1998) Identification of trait-improving quantitative trait loci alleles from a wild rice relative, Oryza rufipogon. Genetics 150:899-909
Yin X, Stam P, Dourleijn CJ, Kropff MJ (1999) AFLP mapping of quantitative trait loci for yield-determining physiological characters in spring barley. Theor Appl Genet 99:244-253

Yin Y, Chasalow SD, Stam P, Kropff MJ, Dourleijn CJ, Bos J, Bindraban PS (2002) Use of component analysis in QTL mapping of complex crop traits: a case study on yield in barley. Plant Breeding 121:314-319

Zeller EJ (1998) Nutzung des genetischen Potentials der HordeumWildarten zur Verbesserung der Kulturgerste (Hordeum vulgare L). J Appl Bot 72:162-167 